\title{
Key Performance Indicators (KPIs) and Shipping Companies Performance Evaluation: The Case of Greek Tanker Shipping Companies
}

\author{
Katerina Konsta $^{1} \&$ Evi Plomaritou ${ }^{2}$ \\ ${ }^{1}$ Doctorate Researcher, University of Plymouth, UK \\ ${ }^{2}$ European University, Geneva, Switzerland \\ Correspondence: Evi Plomaritou, European University, Geneva, Switzerland. Tel: 30-693-8475-006. E-mail: \\ mail@eviplomaritou.com
}

Received: December 11, 2011 Accepted: March 19, 2012 Online Published: May 16, 2012

doi:10.5539/ijbm.v7n10p142

URL: http://dx.doi.org/ijbm.v7n10p142

\begin{abstract}
If you are not sure where you are, how will you find out where to go?

The aim of this paper is to examine the applicability and usefulness of performance indicators in shipping management performance and evaluation.

The paper brings the importance of KPIs closer to the reader and examines their definition, purpose and role in the shipping market. The first part is devoted to literature review on KPIs. The second part is the methodology, where a questionnaire is taken across the tanker shipping companies in Greece. The third part is the analysis of the questionnaire which showed that even though many Greek tanker enterprises recognize the benefits of performance indicators, a small percentage of them use some types of KPIs. The final part is the conclusion.
\end{abstract}

Keywords: Key Performance Indicators (KPIs), shipping companies performance evaluation, shipping marketing, tanker shipping companies

\section{Introduction}

The primary objective of an organization is success, which can be achieved with the appropriate strategy. What being successful means for shipping companies? How will the senior management make sure that objectives are fulfilled and at what extend? Which are the potentials for shipping companies being successful in the future? The assessment of an organization's success potentials should include criteria focused on the market aspects and criteria focused on competitive strength (Ohmae, 1983).

Companies set strategies in order to reach objectives. In return they develop and follow processes in order to realize strategies through the achievement of objectives. This is a never ending cycle. The foundations of success are set by processes. A business process is a set of activities which are performed in order to achieve common aims according to well-defined company objectives (Hammer \& Champy, 1994; Keung \& Kawalek, 1997). These processes contribute towards the achievement of aims and objectives.

During the last 20 years, companies aim at not just earnings but also profitability, and not just winning but retaining customers as well. In order to do that, they must perform satisfactory, making the product or service available on the right place, right time, and right quantity for the right customer.

Nevertheless, what makes a company perform adequately? Are the right processes capable to achieve the right objectives? Does the company perform up to the levels required? That explains why companies employ performance indicators in order to measure, control and improve. In plain English, they need to find and then decide where to go from there. The most successful company is the one that develops cannels that distribute the product or the service to the customer better than the competitor. But how is success measured?

The financial performance is measured by effectiveness and efficiency. Effectiveness is defined as "the degree to which a predetermined objective or target is met" whereas efficiency is given by "the degree to which inputs are used in relation to a given level of outputs" (Foster \& Horngren, 1987, p. 184). Is then improvement a synonymous of effectiveness and efficiency? When a company wants to improve continuously, can they do so by just improving the account numbers? Measures that determine just the financial performance of the company are 
deemed inadequate regarding all business aspects.

\section{Performance Measurement: 20 Years' of Attention}

The concept of performance management is still young and has emerged in the last two decades (Sharif, 2002) as a logical response to the question: "How are our firms performing?" What is known as an old management adage, "you cannot manage what you do not measure" it is the basis of the performance measurements theories. Getting that one step further, "if you cannot measure it, you cannot improve it" (Hamel \& and Prahalad, 1994) illustrates the importance of the right things being measured and the not so important being left out.

Literature review showed that traditional systems, based on transparent financial measures, cannot integrate all factors that are affecting performance of enterprises and organizations (Freeman and Beale, 1992). Performance management is just part of a larger system of business improvement. For an effective system, managers need a balanced set of performance indicators (Kaplan and Norton, 2001).

Performance indicators are compilations of information that are used to measure and assess performance (Edwards and Thomas, 2005). Moreover they indicate the final mark of a company's efficiency and effectiveness. KPIs represent the basis for measuring business and project success. Their purpose is to enable the measurement of performance within companies and the industry, and to initiate benchmarking. Besides direct advantages, KPIs are used as means of communication within stakeholders to inform them about constant improvement endeavors (Vukomanovic et al., 2010).

There are seven reasons why performance measurement is used in the management world: the changing nature of work; increasing competition; specific improvement initiatives; national and international quality awards; changing organizational roles; changing external demands; and the power of information technology (Neely, 1998). Other reasons - under the umbrella of aligning business activities to the strategy of the organization performance against strategic goals, are: increase focus on strategy and results, measure what matters and improve performance, align strategy with what human resource can do, improve communication, and put in priority projects.

Maskell, suggests that performance measurement systems must have the following characteristics (Maskel, 1991; University of Warwick, 2006):

1) They are directly linked to overall business strategy and the company's critical success factors

2) They combine both financial and non financial measures

3) They use different measurements for different areas of the company

4) They are changed over time to reflect changes in strategy and operation

5) They are simple and easy to use

6) They give fast feedback to operators and managers

7) They are intended to teach rather than monitor \& control

8) They use benchmarking to set target characteristics of performance measurement systems found in world class companies.

Research in manufacturing has shown that the frameworks in performance measurement systems refer to: quality, customer service, delivery, process time, dependability, speed, cost, flexibility and resource utilization. The company will decide which and how many different measures are needed. Table 1 describes the evaluators that may be used in terms of capacity management, scheduling and delivery in manufacturing.

Throughout the last twenty years various models have been developed to measure the performance of organizations, such as the BSC, the BEM, the KPI, the Capability Maturity Model (CMM), and the Six Sigma. All models have achieved considerable success with regard to the improvement of different sectors organizations' performance (Meng \& Minoque, 2011), but the KPI model is more popular with financial management practitioners and organisations. In addition to the selection of effective performance models, the proper selection of performance indicators is also important to the measurement and improvement performance (Meng \& Minoque, 2011).

Models, like the European Foundation for Quality Management (e.g. EFQM excellence model), have divided performance indicators on leading, lagging and perceptive measures (Plomaritou et al. 2006). Leading measures are indicative performance measures that assess unfinished processes. Lagging measures are those measures that report accomplished performance and final outcomes and as such they are not able to change the future outcome. Perceptive measures are those measures that report stakeholders' perception in projects and can be lagging or 
leading (Vukomanovic et al., 2010).

Table 1. Measures used in Manufacturing

\begin{tabular}{lll}
\hline $\begin{array}{l}\text { Capacity } \\
\text { management }\end{array}$ & Time related: & $\begin{array}{l}\text { customer service time, cycle or process time, set up times, machine } \\
\text { down-time, time spent on preventative maintenance/total time spent on } \\
\text { maintenance, time between overhauls of machinery, value added, actual } \\
\text { versus theoretical throughput time. }\end{array}$ \\
& Cost related: & $\begin{array}{l}\text { output per equipment, output per metre, output per total labour, cost per } \\
\text { operation hour, cost of machine down time, distance travelled, variance }\end{array}$ \\
against budget, overtime hours/total hours, overtime costs/total payroll \\
cost, Non value adding activities, direct labour productivity and \\
overhead efficiency.
\end{tabular}

Source: (University of Warwick, 2006)

Table 2. Performance Measurement Techniques

\begin{tabular}{|c|c|c|c|c|}
\hline Techniqu & What it does & Aim \& Development & Sectors & Shortcomings \\
\hline 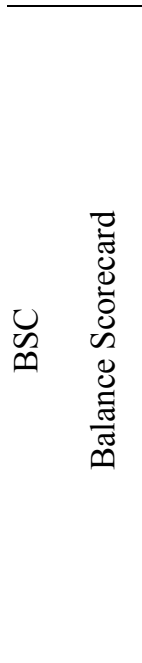 & $\begin{array}{l}\text { Introduced in } 1992 \\
\text { As a tool to support } \\
\text { strategic management } \\
\text { Focuses on financial } \\
\text { measurement } \\
\text { Evaluates whether a } \\
\text { business is moving } \\
\text { towards its strategic goal } \\
\text { from four different } \\
\text { perspectives: } \\
\text { (1)financial, (2)customer, } \\
\text { (3)internal business } \\
\text { process, and } \\
\text { (4)learning and growth. }\end{array}$ & $\begin{array}{l}\text { It aims to balance } \\
\text { (a)long-term with short-term } \\
\text { objectives, } \\
\text { (b)financial with non-financial } \\
\text { concerns, and (c)internal with } \\
\text { external environments } \\
\text { It has moved from a pure } \\
\text { performance model to a full } \\
\text { management system with } \\
\text { applications for both public } \\
\text { and private sector organisations } \\
\text { The BSC is often mixed with } \\
\text { the BEM }\end{array}$ & $\begin{array}{l}\text { FTSE (Financial Time } \\
\text { \& Stock Exchange) } \\
100 \text { companies } \\
\text { financial management } \\
\text { researchers and } \\
\text { practitioners } \\
\text { contractors } \\
\text { consultants } \\
\text { education } \\
\text { government } \\
\text { non profit } \\
\text { organisations }\end{array}$ & $\begin{array}{l}\text { Insufficiency } \\
\text { of four } \\
\text { perspectives }\end{array}$ \\
\hline
\end{tabular}


Results - financial, customer

satisfaction, people

1990 was developed by

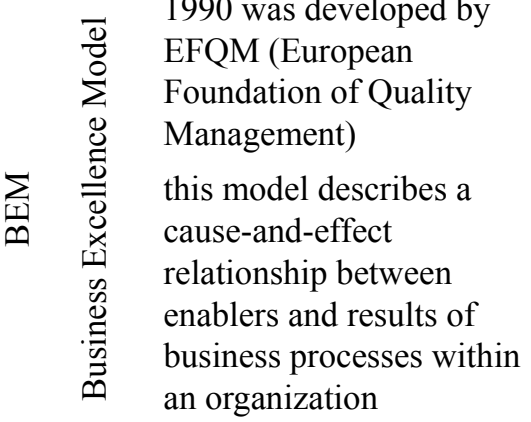

satisfaction, and impact on

society, are achieved through

acting on Enablers -

leadership, policy and strategy, Hotel

people management, resources,

and processes management.

(1) has the ability to

incorporate a number of

initiatives already being

applied by an organisation; and

(2) has an equal focus on

enablers and results.

A performance indicator

is a measure of

performance that focus

on critical aspects of

outputs or outcomes

As a performance measurement system

Six Sigma is a disciplined, data-driven approach and methodology for eliminating defects (driving toward six standard deviations between the mean and the nearest specification limit) in any process -from manufacturing to transactional and from product to service.

Six Sigma is a business management strategy originally developed by Motorola, USA in 1986.

The CMM was proposed by the SEI (Software Engineering Institute (SEI) of Carnegie Mellon University) 1991 as a software development evaluation standard
Time, cost and quality were three primary indicators

Different industry sectors

Six Sigma is a rigorous and disciplined methodology that uses data and statistical analysis to measure and improve a company's operational performance by identifying and eliminating "defects

As of 2010, it is widely used in many sectors of industry, although its use is not without controversy.

It enables an

It helps an organisation to identify best practices they currently exhibit and those upon which they need to improve. A capability or a maturity level is a well-defined evolutionary plateau of process improvement for an organization important the cluster of activities to achieve a set of goals considered important

organisation to improve a set of

related processes by

incrementally

addressing successive

sets of process areas Not widely

It enables an used

organisation to

incrementally improve

processes

corresponding to an

individual process

area (or process areas)

Developed by the authors based on (Meng \& Minoque, 2011) 


\section{How Can the Performance of Shipping Companies be Measured?}

Shipping being characterized as a highly competitive industry makes the use of performance indicators extremely important. According to Panayides, the reasons for the increased emphasis on the strategy-performance relationship in shipping include intense competition, the need to attain competitiveness, maximize shareholder wealth, and the requirement to address stakeholder. Consequently it is very important to closely monitor of the performance implications of the adopted competitive strategies (Panayides, 2003).

The boards of directors will make the decision and the senior managers will determine the performance management and information systems (Burgelman, 1991). Thus they must initiate the need and development of performance indicators in order to evaluate and get feedback of their performance, compare it against goals, and benchmark it against competitors.

The choice of the important indicators has impact on the operation and the direction of the organization. Prior to choosing transport performance indicators, the identification of clear objectives, matching the strategy and acceptance of those involved is required. (Išoraitea, 2010)

Profitability as a measure is not capable of discriminating excellence (Panayides, 2003). Performance measurement is multi-dimensional (Chakravarthy, 1986). The best value performance indicators can be used for five dimension performance: (Išoraitea, 2010)

1) Strategic objectives: why the service exists and what it seeks to achieve

2) Costs/efficiency - the resources committed to a service: the efficiency with which they are turned into inputs

3) Service delivery outcomes - how well the service is being operated in order to achieve the strategic objectives

4) Quality - explicitly reflecting user's experience of services

5) Fair access - relating to case and equality of access to service

As with any management decision, indicators must be specific, measurable, achievable, relevant and timely.

Examples for transport indicators include: resource or input indicators, output indicators, result indicators, and impact indicates. Financial measures of performance are inadequate for addressing the overall performance of companies and those reports in company accounts may be flawed and not comparable across companies (Panayides, 2003).

\section{KPIs for Shipping Companies}

The primary target in any supply chain is the customer and shipping is a part of the supply chain (Pesmatzoglou \& Konsta, 2009). Customers for the liner companies are the freight forwarders or manufacturers and for the tramp is the charterer. The KPIs must be customer oriented in marketing or logistical terms. The concept of customer orientation in business markets has attracted attention from both academics and managers and it has been widely used in the marketing discipline. The term customer oriented companies is used to describe how knowledgeable the company is about the clients' needs and how responsive the firm is to them in terms of the continuous value creation and delivery (Plomaritou et al. 2010). The logistics science refers to supply chains customers, availability of the product and customers needs satisfaction. All in all, services must be available at the right time, place, in the right capacity and quality.

KPIs should have the following characteristics (Parmenterg, 2007):

- $\quad$ Nonfinancial measure

- $\quad$ Frequently measured

- $\quad$ Acted on by the CEO and the senior management team

- Understood by all staff

- Ties responsibility to the individual or team

- Has significant impact

- Has positive impact

Polyviou, gives an example on shipping KPI's i.e., the Lost Time Injury Frequency (LTIF), which is a non financial indicator (see Table 3). The company's goal is to keep the LTIF value as low as possible since it will positively affect the company's performance. This will be achieved by lowering off the financial cost associated 
with the treatment of injuries sustained by the crew and the resulting loss in productivity. Furthermore, the financial cost can be reduced by improving training and security procedures which can lead to fewer accidents, higher morale and increased productivity for the crew. Finally, keeping LTIF value as low as possible, it will satisfy both oil majors and ship owners (Polyviou, 2011).

Since KPIs are the tools for improvement of performance, shipping companies should acknowledge one common set of KPIs, and implement them systematically and methodologically. The shipping industry has moved a step nearer to a "common set of KPIs" in an effort to arrive at a broad-based way of measuring the performance of ships.

Table 3. Shipping KPI example: Lost Time Injury Frequency (LTIF)

\begin{tabular}{llrl}
\hline Step 1 & $\begin{array}{l}\text { Identifying and } \\
\text { calculating a set } \\
\text { of KPIs }\end{array}$ & $\begin{array}{l}\text { An indication of the time lost due to various types of injury sustained by crew } \\
\text { members }\end{array}$
\end{tabular}

(How?)

It is derived for a specific period of time based on the total number of injuries, the total number of crew on board the company's vessels and the total number of hours in the selected time period.

(When?)

Its value is constantly updated based on information such as crew members signing on and off vessels and reported injury incidents

Step 2 Evaluate Set boundaries of acceptability

Does the value of a KPI begin to slide precipitously close to the boundaries of acceptability?

Step 3 Take action Empower alerted user to investigate the root causes of the problem

(Action must be

Decide on appropriate corrective action. straightforward to be understood by all staff involved)

Starts to rise

the CEO or the head of the Marine \& Safety department would have to take action

a review of training and safety procedures or a competence evaluation of implicated officers

Rising value of The indicator can serve as a warning sign for its captain, LTIF for a specific who is the person responsible for keeping it as low as vessel possible.

Source: (Polyviou, 2011)

More specifically, the InterManager's Ship Performance Indicator Standard has been developed over the last years and was released in the end of 2008. Intermanager (www.intermanager.org) is the caretaker of the standard and is hosting the governing body of the standard. It is not an international standard in the sense that it is adopted by an international standardization body. The proposed stand is aimed at becoming a de facto Industry Standard. The objective of the Shipping KPI project is to create a KPI standard that is suitable for (Garfield, 2009):

- Internal Improvement Processes

- External Communication about Performance

The applications of the results from standardising the performance measurements within the shipping industry are the Internal Improvement, Benchmarking, Performance Based Contracting and Building of Public Awareness (Mathews, 2011).

Individual ship data will be entered by ship managers or shipowners in a web based system, initially voluntary and the KPIs will be automatically measured. Once this database works, each ship will be able to measure its KPIs and improvements in performance overtime. It will enable owners to compare ships with all others globally or all those in a certain category, including flag (Garfield, 2009). 


\section{Research Methodology}

The primary objective of this research is to investigate whether key performance indicators are applied by Greek tanker shipping companies and to what extent. The paper also identifies how KPIs were used by tanker shipping companies and how these companies defined their overall performance measurement. Another objective of this research is the study of the benefits offered by the indicators to the above mentioned companies.

The basic characteristic of the tanker market is the dominant role played by a small number of big charterers, that is, the big oil companies. It is worth noting that the oil terminals are controlled by oil companies (state and private) and as a result the market is controlled by them. Tankers, also, are obliged to comply with strict safety rules due to the hazardous potential of their cargo. Under these conditions, key performance indicators in the tanker shipping companies are of special importance to the extent they positively influence the efficiency and effectiveness of vessels.

Primary information was collected through a quantitative research. From the techniques of filling in a questionnaire, their electronic sending was chosen, which means anonymity, allows absolute control on the formulation of questions, does not pressurize the participants in terms of time and minimizes partiality which might exist in the case of physical presence. More specifically, a questionnaire was sent by email to the Greek tanker shipping companies. The determination of the appropriate size of the sample was based on the principles of the science of statistics. The Greek tanker market comprises 135 tanker companies from which forty tanker companies were randomly selected from the Greek Shipping Directory (Skolarikos, 2010); 14 of these companies agreed to participate in the study resulting in a response rate of $10,3 \%$ of the population size. The above mentioned rate gave statistically reliable results, since in accordance to the principles of the science of statistics, $5 \%$ of the population size gives good results.

Structural design was adopted in the questionnaire making it easier to be answered and reach high return rate. The study questionnaire was divided into two parts. The first part contained background of the companies and the second part included information regarding the implementation of key performance indicators in shipping companies. The questions provided up-to-date information on contemporary ship management practice allowing a deeper understanding of its context.

\section{Analysis of Research Results}

Regarding the type of respondents' shipping activity (Figure 1), 12\% of the respondents are third party ship management companies; while $88 \%$ have the ownership and management of its tankers.

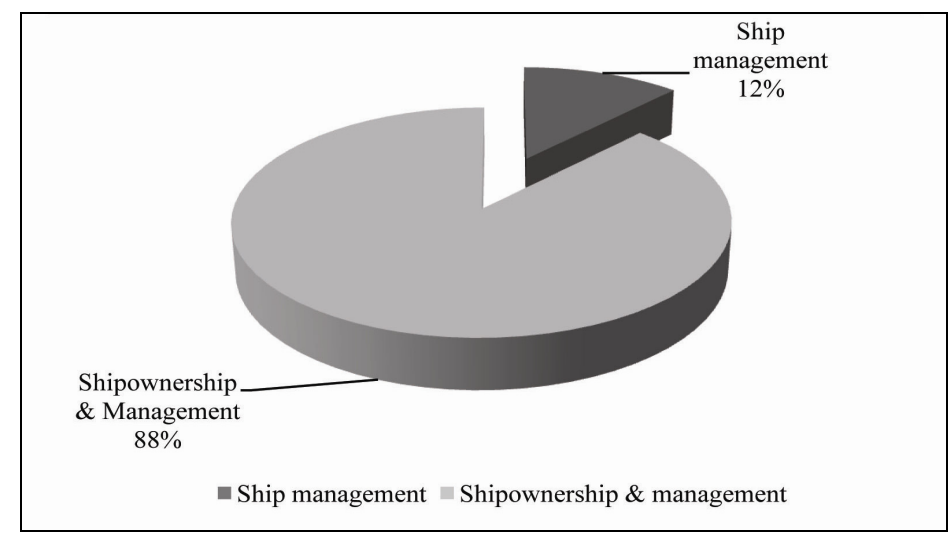

Figure 1. Type of Respndents' Shipping Activity

In order to classify the tanker enterprises in small, medium and large companies, the following criteria were taken into consideration:

1) Total GRT managed by each company

2) Number of employees of each company

Figure 2 presents the distribution of the companies' size in the sample. More specifically, $45 \%$ of the respondents

are large tanker companies, $35 \%$ are medium tanker companies and $20 \%$ are small tanker companies. 


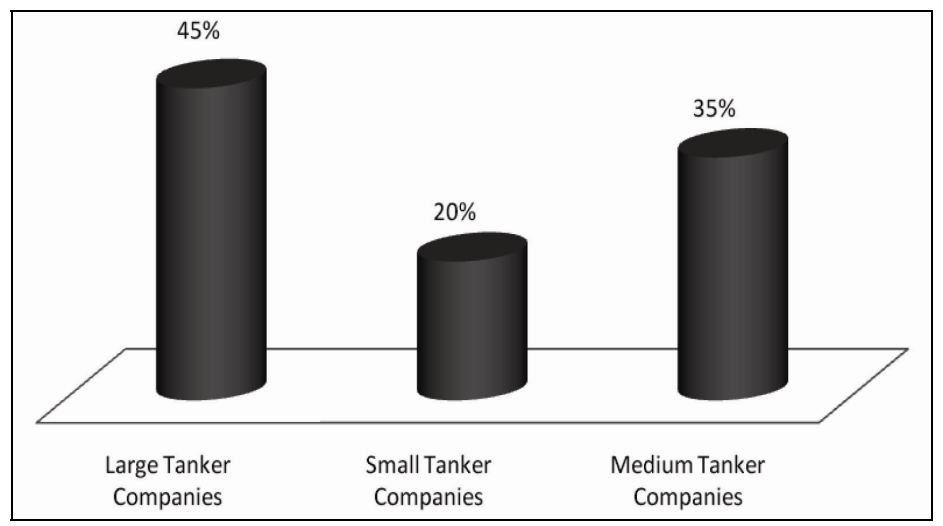

Figure 2. Size of Shipping Companies

As far as the selection model of the tanker companies is concerned (Figure 3), $62 \%$ of the participants answered that they apply the selective specialization, where the companies offer their transportation services to a number of market segments. Most of them manage tankers as well as bulk carriers. The segmental concentration is applied by the $38 \%$ of the participants, where the companies select to offer their sea transport services only to the tanker market.

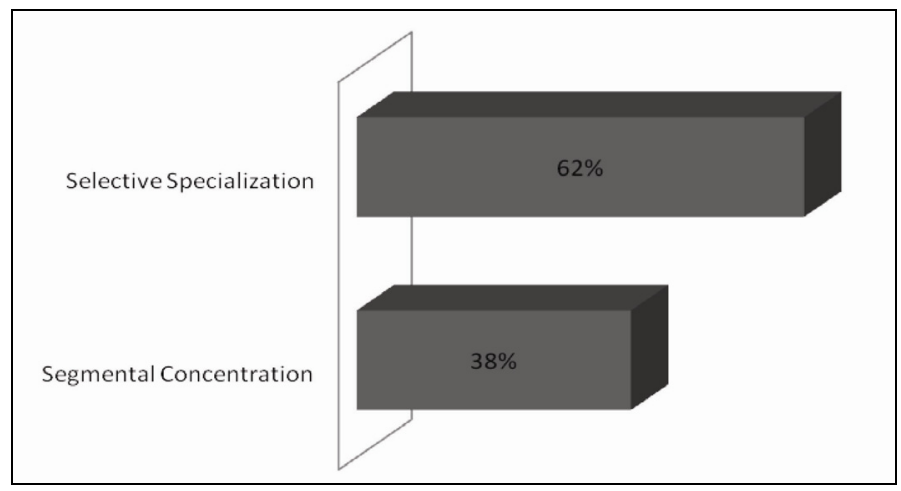

Figure 3. Selection Model of Respondents

Figure 4 presents that $72 \%$ of respondents believe in KPIs' necessity, while $28 \%$ of respondents do not hold such a view. More specifically, 55\% of KPIs' exponents consider that the indicators are more necessary in tanker shipping companies. However, $25 \%$ of KPIs' exponents argue that the indicators are more necessary in large shipping companies and $20 \%$ of KPIs' exponents maintain that the indicators are necessary in shipping companies irrespective of the size and type of managed fleet (Figure 5).

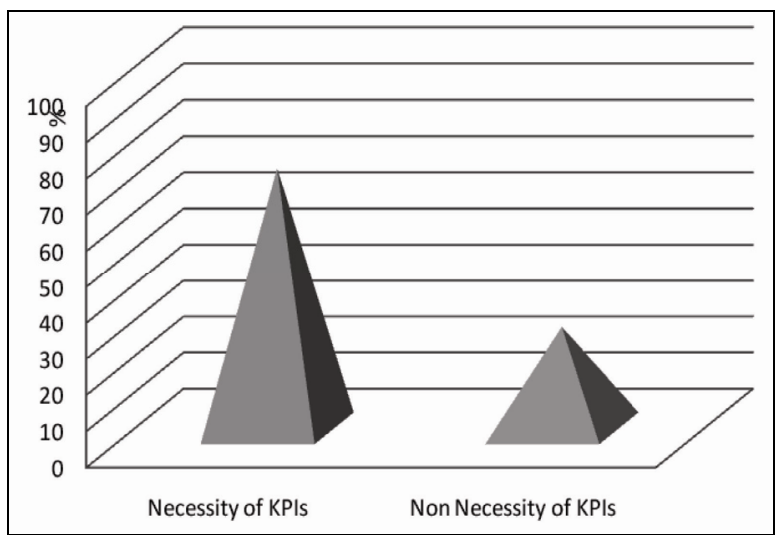

Figure 4. Necessity of KPIs 


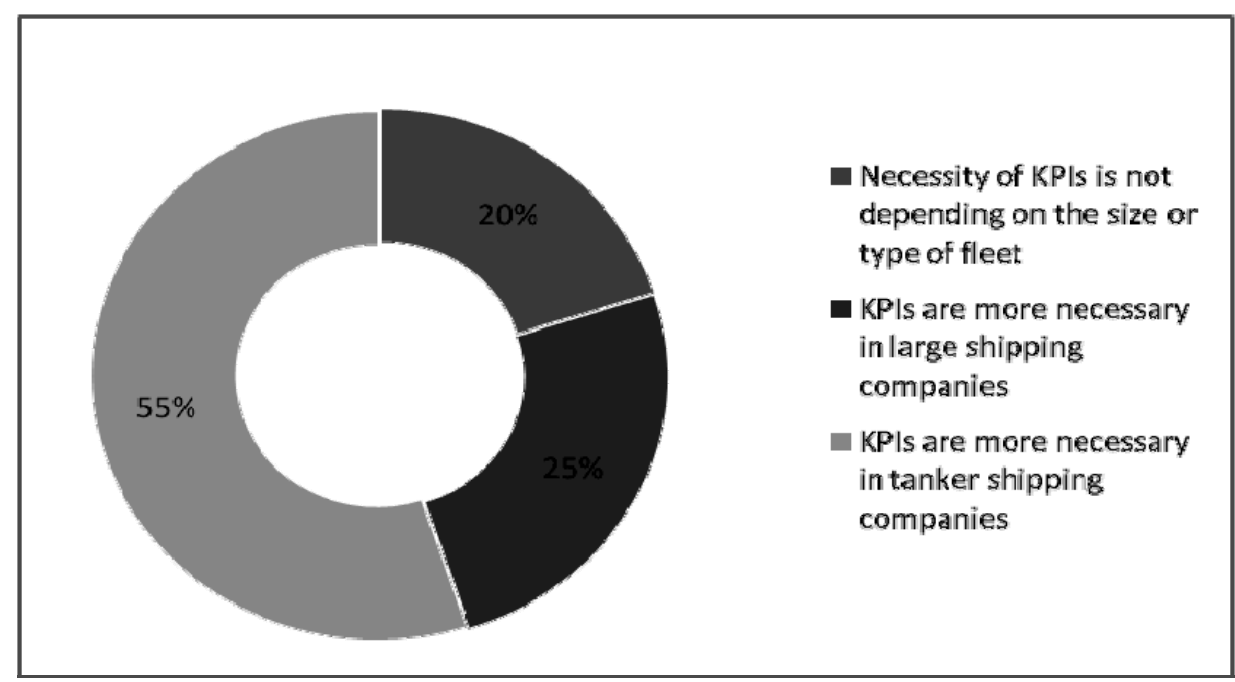

Figure 5. Necessity of KPIs in Relation to Fleet

Figure 6 shows that $22 \%$ of tanker companies apply key performance indicators in their daily managerial tasks, while Figure 7 presents that $69 \%$ of the above mentioned enterprises are large, $27 \%$ are medium and $4 \%$ are small tanker companies.

Figure 8 presents the areas which should be covered by KPI measurement in large, medium and small tanker companies. More analytically, KPI measurement should cover operational, financial, crew/personnel and legislation areas. The most important data provided by KPIs in large, medium and small tanker companies are the operational as well as the legislation data.

KPIs are dependent on the kind and size of fleet that a company manages. One reason for that is the type of regulations instituted by the International Maritime Organizations, which varies according to the type and size of vessels. Therefore, requirements and measurements are different amongst the shipping companies. Although some specific KPIs are common to all shipping enterprises, Figure 9 shows that large tanker companies carry out performance measurements into a greater extent comparing with the small and medium tanker companies. The small number of KPIs that are used by the tanker companies does not vary significantly among the respondents.

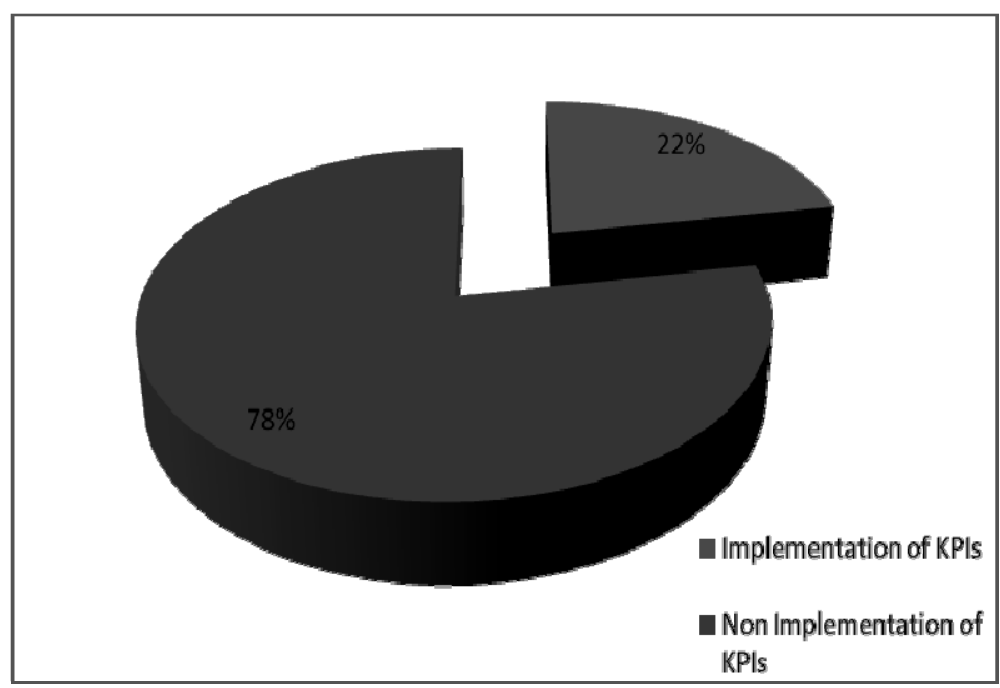

Figure 6. Implementation of KPIs in Tanker Shipping Companies 


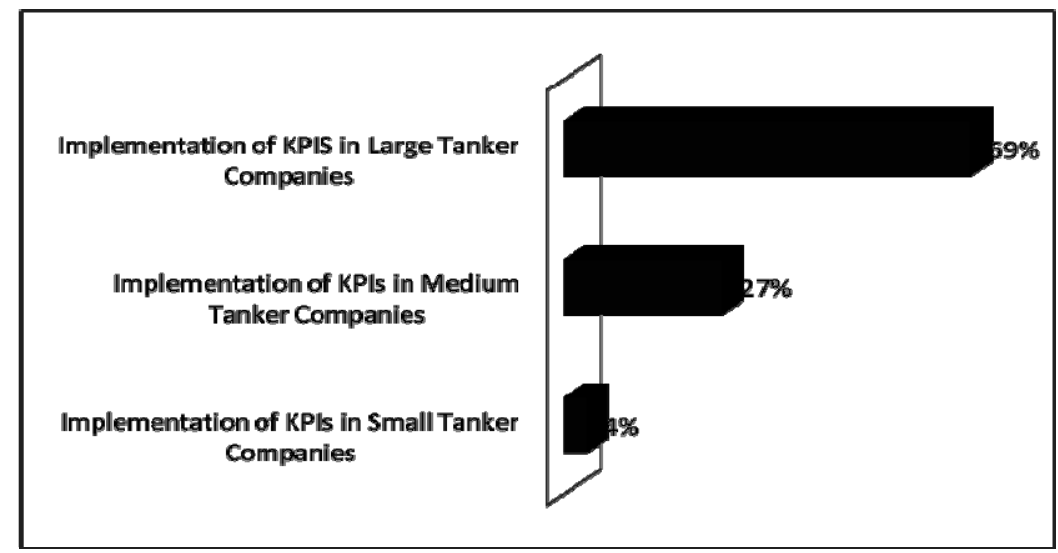

Figure 7. Implementation of KPIs in Large, Medium and Small Tanker Companies

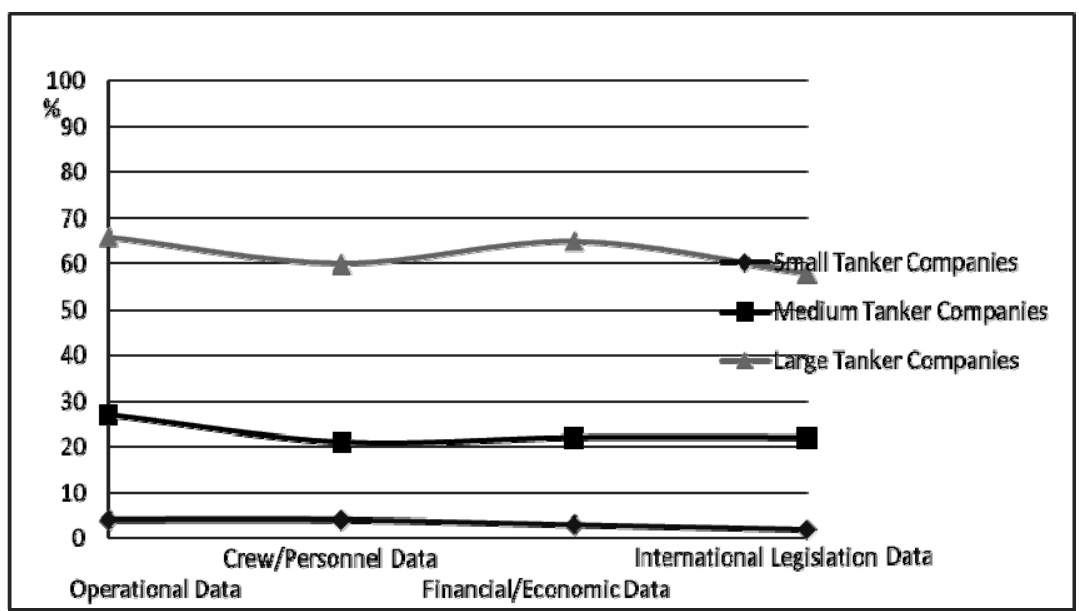

Figure 8. Data Provided by the Mechanism of KPIs to Small, Medium and Large Tanker Companies

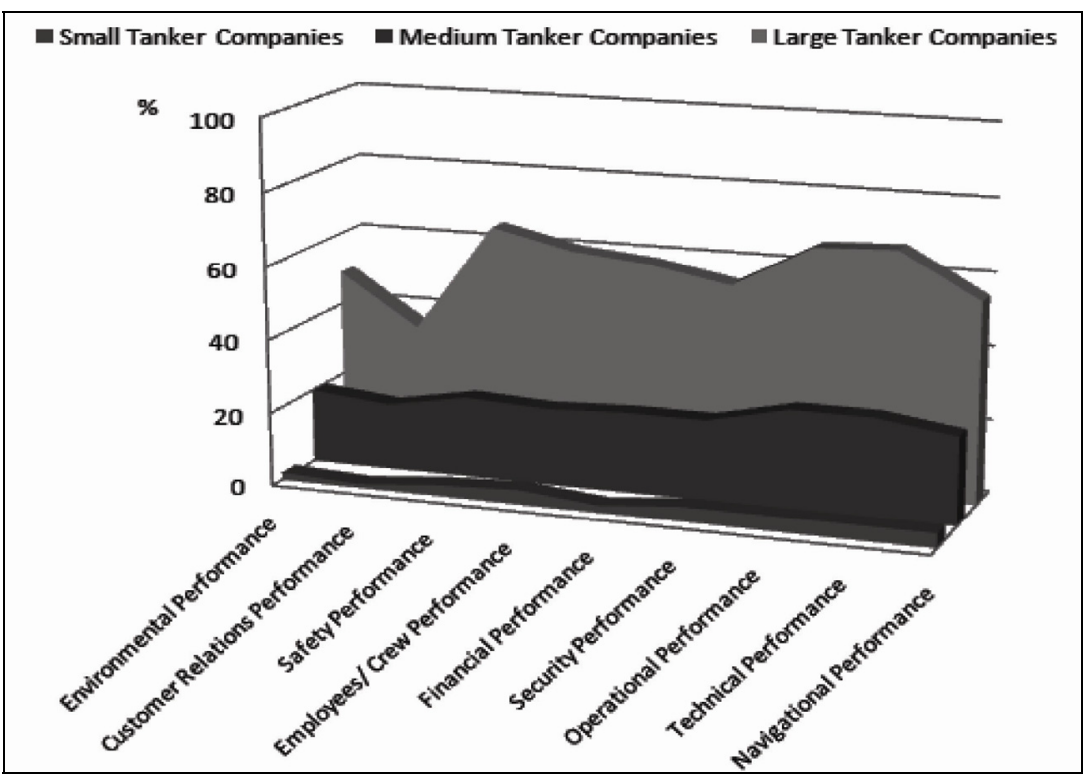

Figure 9. Performance Indicators in Large, Medium and Small Tanker Companies

The most important performance indicators are safety, operational and technical, while the less important are 
customer relations performance indicators. Other types of indicators are environmental, navigational, security, financial and employees/crew performance indicators. At this point, it is recognized that each of the individual KPIs influences others (Latorre et al 2010). For example, safety is related to cost. It is known that a ship manager has to adhere to national and international regulations that constantly change. As changes are implemented in the shipping industry due to legislation insisting on safety precautions, safety measurements will also increase. As a result, the increase in safety means an increase in cost (however, in the long term, increased safety will decrease cost due to marine accident prevention). Furthermore, raised safety performance measurements lead to raised operational and technical performance measurements. Another example is the relation of customers' (charterers) satisfaction to financial performance. Strong customers' relationships and a well reputation of the company in the shipping market lead to the repeat of a profitable charter with the charterer (Plomaritou, 2008).

Regarding the benefits provided to the KPIs users (Figure 10), 14\% of the respondents answered the access to a common pool of accurate, timely information which allows decision makers to monitor progress and take corrective actions promptly. In this way, $13 \%$ of respondents argued that KPIs' mechanism contributes to the minimization of errors. Furthermore, $10 \%$ of respondents consider that KPIs are necessary tools for decision makers. It is widely accepted that effective performance measurement should provide decision makers with information regarding how well the various objectives are being achieved (Santos et al., 2002). Managers have two obstacles when making optimal decisions regarding company's objectives. The first is that the shipping industry is complex and the complexity lies in its high cyclicality, volatility and unpredictability. The second, involves the human capacity to process information; the rationality of human decision-making is bounded and humans make decisions on the basis of selective information as their cognitive abilities are overwhelmed by the complexity of the system (Sterman, 2000).

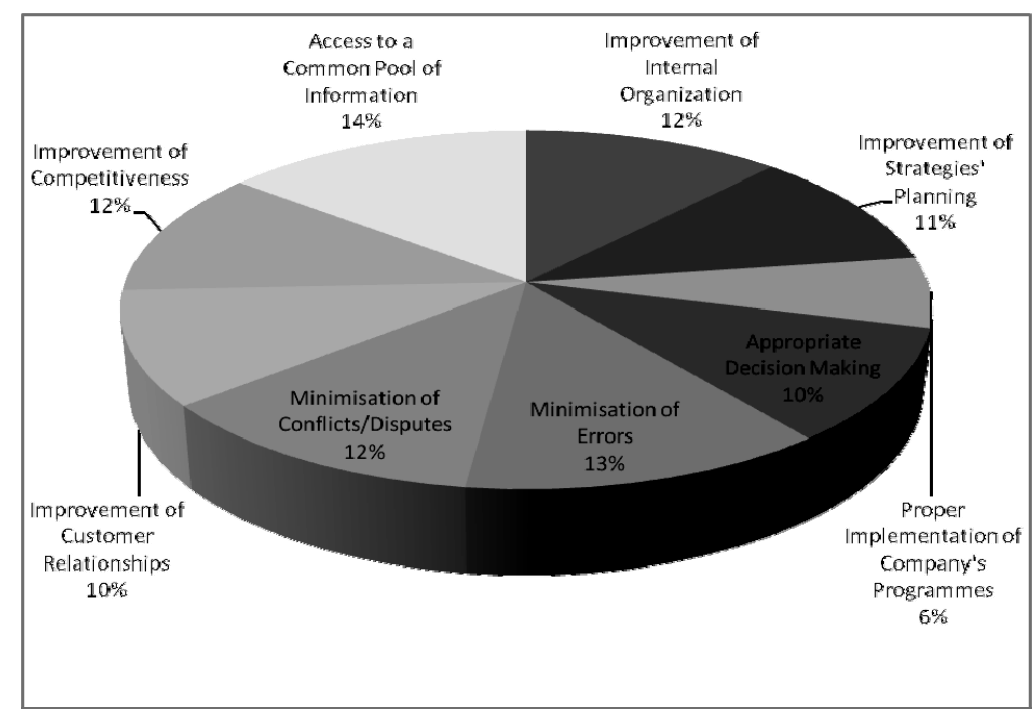

Figure 10. Benefits of KPIs in the Tanker Shipping Company

Furthermore, $12 \%$ of respondents think that the KPI measurements conduce to the minimisation of disputes as well as to the improvement of competitiveness. In addition, $10 \%$ of respondents argued that KPIs lead to improvement of customer relationships. A numerical scale of quantifying customer' (charterer-shipper) satisfaction minimises customer complaints, create customer loyalty and improve customer relationships. Many shipping companies, nowadays, make a systematic effort to acquire information about their customers' perceptions of quality and other attitudes to the company. The results of these polls are used primarily in shipping marketing (Plomaritou et al., 2011).

Moreover, $11 \%$ of respondents claim that an important advantage of KPI measurements is the improvement of strategies' planning. The development of setting goals in terms of KPIs assists the strategies' planning process. By using KPIs the company's objectives are translated into, and measured by, a set of targets for the manager to be achieved. Moreover, $6 \%$ of respondents consider that KPIs contribute to the proper implementation of company's programmes and $12 \%$ of respondents think that KPI measurements conduce to the improvement of internal organization. 
Concerning the success factors of a KPIs' mechanism (Figure 11), 36\% of respondents answered the minimum cost of implementation, $33 \%$ of respondents argued the speed of implementation and $31 \%$ of respondents consider the flexibility of KPI process.

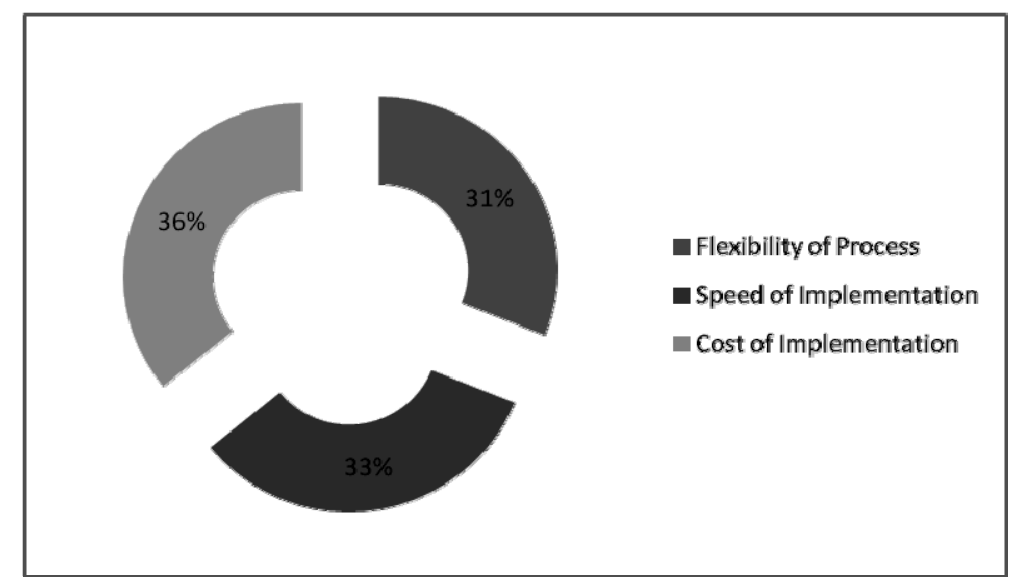

Figure 11. Success Factors of a KPI Process

\section{Conclusion}

The findings of this research are the following:

- The questionnaire taken across tanker shipping companies in Greece, showed that $72 \%$ of respondents believe in KPIs' importance, but only $22 \%$ of tanker companies apply key performance indicators in their daily managerial tasks.

- Furthermore, $69 \%$ of the companies that implement KPIs are large, $27 \%$ are medium and $4 \%$ are small tanker companies.

- The survey also showed that the use of KPIs is the prerequisite for improving internal organization, customer relationships, competitiveness and strategy planning.

- Even though many Greek tanker shipping companies recognize the benefits of performance indicators, a small percentage of them use some types of KPIs.

- KPIs in tanker market are still evolving.

- Tanker companies should acknowledge one common set of KPIs, implement them more systematically and thus improve their performance. Therefore, in the following years, researchers in cooperation with shipping market practitioners should try to integrate performance measurement systems and thus form a unified model of KPIs for performance management.

- Projecting the above point to all shipping companies since KPIs are the tools for improvement of performance, all shipping companies should acknowledge one common set of KPIs, and implement them more systematically and methodologically. Benchmarking can thus be achieved and all parties in the market can benefit.

- The KPIs must be customer oriented in marketing or logistics terms.

- On an overall supply chain perspective, the research evidences that the performance measurement should not go under the arms' length of the supply chain but it should take under consideration the final customer/consumer of the product (charterer and freight forwarder). The successful shipping company is the company which can define and satisfy the needs and the wants of the customers by making available its service at the right time, place, in the right capacity and quality. The successful shipping company must utilize to the maximum its resources in order to provide its customers with the "rights": right product, right quality, right condition, right place, right time, right customer and right cost.

This paper has verified and established the need for increased efficiency in the shipping industry and the role that Key Performance Indicators (KPIs) have in driving these required efficiencies 


\section{References}

Burgelman, R. A. (1991). Intraorganisationalecol ogy of strategy making and organisaorganisational adaptation:theory and field research. Organisational Science, 2, 239-262. http://dx.doi.org/10.1287/orsc.2.3.239

Chakravarthy, B. S. (1986). Measuring strategic performance. Strategic Management, 27, 485-510.

Foster, G., \& Horngren, C. T. (1987). Cost Accounting: A Managerial Emphasis. Prentice Hall International.

Garfield, G. (2009). Ship Comparison Plan Progressing. Tradewinds, 3 July 2009, 26.

Hamel, G., \& Prahalad, K. (1994). Competing for the Future. Boston, Massachusetts: Harvard Business School Press.

Hammer, M., \& Champy, J. (1994). Reengineering the Corporation - A Manifesto for Business. London: Nicholas Brealey.

Išoraitea, M. (2010). Analysis of transport performance indicators. Transport, 20(3), 111-116.

Kaplan, R. S., \& Norton, D. (2001). The Strategy - Focused Organization. Harvard: Harvard Business School Press.

Keung, P., \& Kawalek, P. (1997). Goal-based Business Process Models: Creation and Business Process. Management Journal, 3(1), 17-38.

Latorre, M., Roberts, M., \& Riley, M. J. (2010). Development of a Systems Dynamics Framework for KPIs to Assist Project Managers' Decision Making Processes. Revista de la Construction, 9(1), 39-49.

Maskel, 1. B. (1991). Performance Measurement for World Class Manufacturing. Cambridge, Massachusetts: Productivity Press.

Mathews, S. (2011). Intermanager's Shipping KPI Project Poised for Breakthrough. Retrieved from http://www.intermanager.org/2011/07/intermanager\%E2\%80\%99s-shipping-kpi-project-poised-for-breakthr ough/

Meng, X., \& Minoque, M. (2011). Performance Measurement Models in Facility Management: a Comparative Study. Facilities, 29(11/12). http://dx.doi.org/10.1108/02632771111157141

Neely, A. (1998). Three Models of Measurement: Theory and Practice. International Journal of Business Performance Management, 1(1), 47-64. http://dx.doi.org/10.1504/IJBPM.1998.004544

Ohmae, K. (1983). The Mind of the Strategist. Harmondsworth: Penguin Books.

Panayides, P. M. (2003). Competitive strategies and organizational performance in ship. Journal of Maritime Policy \& Management, 20(2), 123-140.

Parmenterg, D. (2007). Key Performance Indicators: developing, implementing, and using winning KPIs. Wiley.

Pesmatzoglou, M., \& Konsta, K. (2009). Information and Technology Usage in globalised personal and business Environments: A Greek perspective. International Conference on Applied Business and Exonomixa, ICABE (p. 484). Kavala: Kavala Institute of Technology.

Plomaritou, E. (2008). Marketing of Shipping Companies. Recommended by the Institute of Chartered Shipbrokers. Athens: Stamoulis Publications.

Plomaritou, E., Gortzis A., \& Tsakonas, N. (2006). Shipping Organizations Framework for Internal Assessment. Athens: European Business Ethics Network Publications.

Plomaritou, E., Plomaritou, V., \& Giziakis, K. (2011). Shipping Marketing \& Customer Orientation: The Psychology \& Buying Behaviour of Charterer \& Shipper in Tramp \& Liner Market. Journal of Management, 16(1), 57-89.

Polyviou, S. (2011). Developing key performance indicators and information dashboards for the maritime industry. Retrieved from http://www.busmanagementme.com/article/Developing-key-performance-indicators-and-information-dashb oards-for-the-maritime-industry/Cosine Consultants Ltd

Santos, S., Belton, V., \& Howick, S. (2002). Adding Value to Performance Measurement by Using System Dynamics and Multi-Criteria Analysis. International Journal of Operations and Production Management, 22(11), 1246-1272. http://dx.doi.org/10.1108/01443570210450284 
Sharif, A. M. (2002). Benchmarking Performance Management Systems. International Journal of Benchmarking. 9(1), 628-642.

Skolarikos, (2010). Greek Shipping Directory. Athens: Greek Shipping Publications Co. Ltd.

Sterman, J. D. (2000). Business Dynamics: Systems Thinking and Modeling for a Complex World. New York: Irwin McGraw-Hill.

University of Warwick. (2006). Performance Measurement \& Costing. In Logistics \& Operations Management.

Vucomanovic, M., Radujkovic, M., \& Nahod, M. (2010). Leading, Lagging and Performance Measures in the Construction Industry. International Journal of Organization, Technology and Management in Construction, 2(1), 103-111. 